\title{
DIREITOS FUNDAMENTAIS NO REINO UNIDO: \\ UM ESTUDO DO HUMAN RIGHTS ACT
}

Daniel Martins Felzemburg

\section{Introdução}

A presente exposição pretende fazer uma análise dogmática dos direitos fundamentais no Reino Unido após a implementação e vigência do Human Rights Act em outubro de 2000. Diploma normativo relativamente novo, o Human Rights Act tem suscitado interesse na comunidade jurídica, assim como "intensa é a polêmica que provocou, polêmica evidentemente ainda em curso." 1

Para atingir o escopo deste trabalho, far-se-á uma abordagem sobre o impacto do Human Rights Act perante o Monarca, o Parlamento, e o Judiciário britânico. Será dedicado, ainda, um capítulo específico para análise da eficácia dos direitos fundamentais no Reino Unido diante do referido diploma legal.

Não se pretende, aqui, exaurir o estudo sobre o Human Rights Act, visto que estaríamos fugindo do objetivo da presente exposição. No entanto, espera-se dar uma modesta contribuição para um tema tão importante e em destaque atualmente no cenário internacional.

\section{O Human Rights Act}

Antes de tudo, é importante fazer um curto esboço sobre o Human Rights Act, especialmente sobre a sua origem e natureza jurídica.

\footnotetext{
* Advogado. Mestrando em Direito das Relações Internacionais pelo UNICEUB. Especialista em Direito Processual Civil pelas Faculdades Jorge Amado, Salvador-BA. Sócio efetivo da Academia Brasileira de Direito Processual Civil. E-mail: danifelze@hotmail.com.

${ }^{1}$ FERREIRA FILHO, Manoel Gonçalves. Inovações na constituição inglesa: o human rights act, 1998. In: Revista brasileira de direito constitucional, n. 4, pp. 49-55, jul./dez. 2004, p. 49.

PRISMAS: Dir., Pol.Pub. e Mundial., Brasília, v.3, n, 2, p. 217-242, jul/dez.2006 
Origem

Segundo leciona Dawn Oliver, ${ }^{2}$ o Human Rights Act foi uma das primeiras Cartas a ser introduzida na Casa dos Comuns após as eleições gerais de 1997, passando a vigorar no Reino Unido a partir de outubro de 2000. Mas a causa de sua criação remonta a tempos muito mais antigos. Isto porque o que fez o Human Rights Act foi incorporar à lei interna do Reino Unido as principais cláusulas da Convenção Européia de Direitos Humanos ("European Convention on Human Rights"), instrumento internacional que foi adotado por muitas democracias do oeste europeu a partir de 1950.

A Convenção Européia de Direitos Humanos foi ratificada pelo Reino Unido em 1951, vigorando internacionalmente em 1953. Os britânicos exerceram um papel importante na criação da Convenção Européia, já que naquela época o objetivo era prevenir uma nova onda de abusos aos direitos civis e políticos que aconteceram antes e durante a Segunda Guerra Mundial sob os regimes nazistas e fascistas, além de prevenir a expansão do comunismo e autoritarismo do bloco soviético. ${ }^{3}$

Não obstante, as normas da Convenção Européia não podiam ser invocadas perante as cortes britânicas até que fossem incorporadas numa lei interna. E o direito individual de petição à Corte Européia de Direitos Humanos em Estrasburgo, previsto na Convenção Européia, foi fundamental para que o Reino Unido incorporasse tais normas ao direito interno através do Human Rights Act.

Com efeito, o direito individual de petição à Corte Européia de Direitos Humanos em Estrasburgo não foi inicialmente ratificado pelo Reino Unido, o que trazia como conseqüência o fato de que os casos envolvendo o Reino Unido somente poderiam ser levados àquela corte internacional através de outros países participantes. ${ }^{4}$

\footnotetext{
${ }^{2}$ OLIVER, Dawn. Constitucional reform in the UK. Nova York: Oxford University Press, 2003, p. 111.

3 Os direitos originalmente previstos na Convenção Européia estavam ligados a um sistema liberal de democracia. (OLIVER, ob. cit., p. 111). Posteriormente, foram incluídos outros direitos, através de Protocolos, tais como o de proteção à propriedade privada, à educação, a eleições livres, a abolição da pena de morte, dentre outros (FERREIRA FILHO, ob. cit., p. 52).

${ }^{4}$ Como foi o caso de Irlanda x Reino Unido (1978), no qual o governo irlandês reclamou das técnicas de interrogação utilizadas pelas forças de segurança do Reino Unido na Irlanda do Norte, violando o direito contra a tortura e tratamento desumano e degradante previsto na Convenção Européia (OLIVER, ob. cit., pp. 111/112). Quem assistiu ao filme "Em nome do pai", pode ter uma boa noção deste caso.

PRISMAS: Dir., Pol.Pub. e Mundial., Brasília, v.3, n, 2, p 217-242, jul/dez.2006 
Após o direito individual de petição ter sido aceito pelo governo do Reino Unido, muitos casos foram trazidos com êxito à Corte de Estrasburgo por vítimas das violações dos direitos da Convenção Européia. ${ }^{5}$

Dessa maneira, o fato de os direitos violados no Reino Unido só poderem ser protegidos perante a Corte de Estrasburgo, aliado ao alto índice de condenação do país nos casos levados naquela Corte, acabou por pressionar o governo a incorporar os direitos da Convenção Européia ao direito interno britânico.

Ademais, houve também uma pressão internacional decorrente do processo integrativo do Reino Unido à União Européia, que não poderia ficar "de fora" do bloco comunitário quanto à efetiva proteção dos direitos humanos tutelados pela Convenção Européia.

A adoção do Human Rights Act decorre do processo associativo que integrou a Grã Bretanha na União Européia. Havendo sido por ela subscrita a Convenção Européia dos Direitos do Homem de 1950, mas não tendo as normas desta sido incorporadas numa lei, não podiam elas ser invocadas em juízo contra um ato administrativo, o que constituía uma evidente aberração. ${ }^{6}$

Por fim, o fato de outros países de tradição do common law, como o Canadá e a Nova Zelândia, adotarem antes do Reino Unido a sua própria Carta de proteção dos direitos humanos, ${ }^{7}$ acabou por concretizar a edição do Human Rights Act na Grã Bretanha.

Assim, após sucessivas resistências do governo britânico sustentado pelos Liberais Democratas, em 1996, o Partido Trabalhista, apesar de estar na oposição, colocou em proposta a incorporação dos direitos da Convenção Européia para “[...] enable British people to enforce their rigths in UK courts and enable our own judges to apply the ECHR in their jurisdiction.". ${ }^{8}$ Era o primeiro passo para criação do Human Rights Act.

\footnotetext{
${ }^{5}$ O Reino Unido sempre figurou numa posição preocupante no ranking das violações, segundo os dados estatísticos trazidos por BRADLEY e EWING: "More recent information shows that as of 3 April 1995, the Court had found at least one breach of the Convention on 35 occasions in the case of the UK. This compared with 82 in the case of Italy, 29 in the case of France, 27 in the case of Austria, 23 in the case of the Netherlands, 21 in the case of Sweden and 11 in the case of Germany." (BRADLEY, A.W., and EWING, K.D. Constitucional and Administrative Law. 13 a ed., London: Longman, 2003, p. 413).

${ }^{6}$ FERREIRA FILHO, ob. cit., p. 52.

${ }^{7}$ Respectivamente, o Canadian Charter of Rights and Freedoms 1982 e o New Zealand Bill of Rigths Act 1990. Além desses, o Hong Kong e a África do Sul são outros países do common law que recentemente deram uma proteção constitucional aos direitos humanos (BRADLEY, A.W., and EWING, K.D., ob. cit., pp. 416/417).

8 STRAM, J. and BOATENG, P. Bringing Rights Home, 1996, apud BRADLEY, A.W., and EWING, K.D., ob. cit., p. 416.

PRISMAS: Dir., Pol.Pub. e Mundial., Brasília, v.3, n, 2, p 217-242, jul/dez.2006 


\section{Natureza jurídica}

Manoel Gonçalves Ferreira Filho entende que a natureza jurídica do Human Rights Act é híbrida, pois, para o referido professor,

É lei interna, na sua parte 'procedimental', a que disciplina a declaração de compatibilidade, a declaração de incompatibilidade, e os efeitos das mesmas. É, todavia, norma internacional na sua parte substancial, desempenhando a função de introduzir no plano interno normas oriundas de um Pacto, ato convencional de direito internacional. Note-se que estas normas não se tornam pela incorporação regras internas, exceto quanto à sua aplicabilidade (quando não em choque com regra legal britânica), pois a elas falta o poder de derrogar o direito interno pré-existente. ${ }^{9}$

De fato, o Human Rights Act possui uma parte procedimental, com regras próprias que somente podem ser aplicadas dentro do Reino Unido. As mais importantes normas procedimentais serão estudadas no decorrer do presente artigo.

Mas o que mais importa no Human Rights Act é a sua parte substancial, a razão pela qual ele foi concebido, que foi a incorporação à lei interna do Reino Unido das principais cláusulas da Convenção Européia de Direitos Humanos, dando uma especial proteção legal a certos direitos civis e políticos. Não é por acaso que consta o seguinte no preâmbulo do Human Rights Act:

Um Ato para dar eficácia aos direitos e liberdades garantidas sob a Convenção Européia de Direitos Humanos; para fazer previsões a respeito de certos órgãos judiciais que serão juízes da Corte Européia de Direitos Humanos; e para assuntos conexos. ${ }^{10}$

A incorporação das principais cláusulas da Convenção Européia de Direitos Humanos através do Human Rights Act se fazia necessária, na medida em que o Reino Unido adota um sistema dualista, ou seja, “[...] as fontes e normas do direito internacional não têm

\footnotetext{
${ }^{9}$ Ob. cit., p. 54.

${ }^{10}$ A tradução é nossa. Do texto original consta: "An Act to give further effect to rigths and freedoms guaranteed under the European Convention on Human Rigths; to make provision with respect to holders of certain judicial offices who become judges of the European Court of Human Rights; and for connected purposes." (REINO UNIDO. Human rights act. 1998. 1998 Chapter 42. Crown Copyright 1998. Disponível em: < www.opsi.gov.uk/acts/acts1998/19980042.htm>. Acesso em 2 nov. 2005).

PRISMAS: Dir., Pol.Pub. e Mundial., Brasília, v.3, n, 2, p 217-242, jul/dez.2006 
influência nenhuma sobre questões de direito interno, assim como as normas de direito interno não influenciam questões de ordem externa.". ${ }^{11}$

Portanto, era necessária a incorporação das normas da Convenção Européia através do Human Rights Act a fim de que ganhassem vigência dentro do território do Reino Unido.

E os principais direitos da Convenção Européia incorporados pelo Human Rights Act foram o direito à vida $\left(\operatorname{art.} 2^{\circ}\right)$, a proibição de tortura $\left(\operatorname{art.~} 3^{\circ}\right)$, a proibição da escravidão e do trabalho forçado (art. $4^{\circ}$ ), a liberdade e segurança (art. $5^{\circ}$ ), a um julgamento equânime (art. $6^{\circ}$ ), a legalidade criminal (art. $7^{\circ}$ ), o direito a privacidade (art. $8^{\circ}$ ), a liberdade de pensamento, consciência e religião (art. $9^{\circ}$ ), a liberdade de expressão (art. $10^{\circ}$ ), a liberdade de reunião e o direito de associação (art. $11^{\circ}$ ), direito ao matrimônio (art. $12^{\circ}$ ), a proibição de discriminação (art. $14^{\circ}$ ), a proteção da propriedade privada (art. $1^{\mathrm{o}}$ do Primeiro Protocolo), direito a educação (art. $2^{\circ}$ do Primeiro Protocolo), direito à livre eleições (art. $3^{\circ}$ do Primeiro Protocolo), e à abolição da pena de morte, salvo em tempos de guerra (arts. $1^{\circ}$ e $2^{\circ}$ do Sexto Protocolo).

Com a expressa previsão de tais direitos no Human Rights Act, o Reino Unido acabou por consagrar os direitos fundamentais em seu ordenamento jurídico. ${ }^{12}$ Apesar disso, as normas do Human Rights Act não são hierarquicamente superiores do que as leis do Parlamento. Ao revés, no conflito entre elas, prevalece à norma interna. É a supremacia do direito interno britânico sobre o direito internacional, que será abordada com mais profundidade nos capítulos seguintes.

\footnotetext{
${ }^{11}$ PINHEIRO, Carla. Direito internacional e direitos fundamentais. São Paulo: Atlas, 2001, p. 106. Não confundir o sistema dualista do direito internacional, com o parlamentarismo dualista, que vigorou na Grã Bretanha do século XVIII, “...porque, se o gabinete para manter-se necessitava de apoio parlamentar, para constituir-se dependia da vontade do soberano. Fundava-o assim uma dupla confiança: a do rei e a do Parlamento." (FERREIRA FILHO, Manoel Gonçalves. Curso de direito constitucional. 29a ed., São Paulo: Saraiva, 2002, p. 145). Já o regime parlamentar monista se caracteriza pela predominância de um órgão de poder sobre o outro, onde o gabinete só depende da maioria parlamentar para se sustentar. "A predominância do Primeiro-Ministro, Chefe de Governo, configura o regime parlamentar monista da Inglaterra no século atual." (HORTA, Raul Machado. Direito constitucional. $4^{a}$ ed., Belo Horizonte: Del Rey, 2003, p. 654).

${ }^{12}$ De acordo com a classificação trazida por JOSÉ JOAQUIM GOMES CANOTILHO, segunda a qual os "[...] direitos fundamentais são os direitos do homem, jurídico-institucionalmente garantidos e limitados espaciotemporalmente", diferentemente dos direitos do homem, que "[...] são direitos válidos para todos os povos e em todos os tempos (dimensão jusnaturalista-universalista);" (CANOTILHO, José Joaquim Gomes. Direito Constitucional e Teoria da Constituição. $7^{\mathrm{a}}$ ed., Coimbra: Almedina, 2003, p. 393).
} 


\section{Direitos fundamentais e o monarca}

O sistema de governo do Reino Unido é monarquia constitucional ${ }^{13}$ parlamentarista. Nesse sistema, o Executivo possui estrutura dualista, ou seja, o rei "[...] é o chefe de Estado, com funções de representação, de cerimonial e de conselho, enquanto o governo é exercido por um órgão coletivo, o conselho de ministros ou gabinete.". ${ }^{4}$

No presente capítulo, contudo, somente falaremos sobre a figura do Chefe do Estado, do Monarca, frente ao Human Rights Act. Isto porque o capítulo seguinte será dedicado à análise do Parlamento britânico, que também exerce funções executivas nesse sistema.

Ademais, há que se tomar com ressalvas a assertiva de que o Monarca do Reino Unido exerce apenas funções de Chefe de Estado. É sabido que uma mentira contada diversas vezes acaba virando verdade. Talvez esse ditado se aplique ao velho jargão de que "a Rainha reina, mas não governa". ${ }^{15}$

Em primeiro lugar, é importante registrar que falar da Coroa é falar da história e tradição do Reino Unido. Talvez por isso, até os dias de hoje, o Soberano possua quase os mesmos poderes e prerrogativas de 500 anos atrás, não obstante as diversas transformações que a sociedade britânica passou no tempo.

A justificação histórica é preponderante. É preciso que se entenda que uma sociedade, por mais moderna que possa parecer em suas conceituações de política popular e política externa, não pode ser interpretada, com o mesmo grau de desenvolvimento (a melhor palavra seria modificação), em seus conceitos sócio-morais. O culto à Coroa é intrinsecamente um culto ao tradicional, ao que não se modifica, ao que seja perene, ao que seja intocável, ao que, menos hoje do que antes, seja de inspiração divina. Daí a necessidade de se valorizar a perenidade das instituições e não ignorar totalmente o que seus antepassados lutaram tanto para conquistar. ${ }^{16}$

E dentre os inúmeros poderes e prerrogativas que o Monarca detém, como Chefe de Estado, pode se citar os de receber os representantes da comunidade inglesa ultramar e os

${ }^{13}$ Também chamada de monarquia limitada, em contraposição à monarquia absolutista vigente no Reino Unido do século XVIII. (FERREIRA FILHO, Curso de direito constitucional..., p. 78).

14 "Ultimamente, porém, à testa desse conselho vêm as Constituições pondo um chefe, o primeiro-ministro, presidente do conselho ou chanceler, verdadeiro chefe do governo." (FERREIRA FILHO, Curso de direito constitucional..., pp. 147/148).

${ }^{15}$ Sobre o tema, vide as contundentes críticas de FRANCISCO BILAC M. PINTO FILHO, para quem "Nos poderes exercidos pelos reis e rainhas do Reino Unido reside o maior grau de desinformação daqueles que vivem sob a égide das repúblicas." (PINTO FILHO, Francisco Bilac M.. A Monarquia Constitucional no Reino Unido e a prerrogativa da Coroa. A Desmistificação do honorífico. In: Revista Forense, V. 380, pp. 47-63, jul./agost. 2005, p. 52).

${ }^{16}$ PINTO FILHO, ob. cit., p. 50.

PRISMAS: Dir., Pol.Pub. e Mundial., Brasília, v.3, n, 2, p 217-242, jul/dez.2006 
representantes diplomáticos de outros países, conferir honrarias e condecorações a autoridades e cidadãos, nomear os ocupantes de determinados cargos na administração, dentre outros. ${ }^{17}$

Mas o Monarca também exerce um papel importante na condução política da nação. Dentre as atividades típicas de Chefe de Governo, estão as de dar e receber conselhos do primeiro-ministro, inclusive podendo refutar os aconselhamentos deste nos negócios que dependam de sua aquiescência, embora tal atitude não seja recomendável para a boa governabilidade. O Soberano exerce também poderes emergenciais de convocar tropas e serviços civis para conter situações de emergência, como atos atentatórios ao Estado. ${ }^{18}$

Mas há mais. O Monarca também pode dissolver o Parlamento, ou mesmo recusar o pedido expresso do primeiro-ministro para que o faça, embora tal ato possa representar a renúncia deste ao cargo. ${ }^{19}$

Em relação com os demais poderes do Estado, o Soberano, além de conservar os atos de convocação, prorrogação e dissolução da Câmara dos Comuns, conserva também alguns atos de legislar através dos chamados Orders in Council e Letters Patente. ${ }^{20}$ Quanto ao Poder Judiciário, o Soberano pode nomear membros deste poder para cuidar da administração judiciária, ${ }^{21}$ além de poder conceder o perdão, a remissão e a redução de penas de condenados. $^{22}$

O Soberano tem o poder até de indicar o primeiro-ministro, mas certamente ele indicará aquele candidato que tem mais chances de reunir uma maioria confortável no Parlamento. Para Raul Machado Horta:

A Coroa nomeia, mas não elege; demite e não controla. O poder oculto é a autoridade do povo. A Coroa pode, em tese, escolher livremente o PrimeiroMinistro, mas o Governo não se manterá se a escolha desconsiderar a preferência popular. ${ }^{23}$

${ }^{17}$ BRADLEY, A.W., and EWING, K.D., ob. cit., p. 236.

${ }^{18}$ Questiona-se atualmente se tais poderes do Soberano se conservariam, como no caso de atos terroristas ocorridos em território do Reino Unido. Existe uma regra no sistema do common law de que o desuso de um direito não limita o seu exercício, mas "[...] tem se consolidado a principiologia de que os poderes emergenciais da Coroa somente podem ser exercidos se outros não forem conferidos por lei a outras autoridades estatais." (PINTO FILHO, ob. cit., p. 59).

${ }^{19}$ Idem, p. 55.

${ }^{20}$ Somente está vedado ao Soberano criar novas figuras criminais por meio desses atos normativos, cuja competência exclusiva é do Parlamento. (PINTO FILHO, ob. cit., p. 58).

${ }^{21}$ A criação de novas Cortes de Justiça, contudo, também é de competência exclusiva do Parlamento. (PINTO FILHO, ob. cit., p. 59).

22 Á semelhança dos poderes conferidos ao nosso Presidente da República pelo art. 84, XII, da Constituição Federal, in verbis: "conceder indulto e comutar penas, com audiência, se necessário, dos órgãos instituídos em lei;” (BRASIL. Constituição Federal -Código Civil -Código de Processo Civil. Organizador Yussef Said Cahali. 5. ed. ver., atual. e ampl. São Paulo: RT, 2003, p. 72).

${ }^{23}$ HORTA, ob. cit., p. 662.

PRISMAS: Dir., Pol.Pub. e Mundial., Brasília, v.3, n, 2, p 217-242, jul/dez.2006 
Como não poderia ser diferente, o Human Rights Act não esqueceu de fazer referência à Coroa. Ao contrário, dedicou na seção 5 um capítulo expresso sobre o direito da Coroa intervir ("Right of Crown to intervene"), dentre outras referências esparsas encontradas no referido diploma legal.

De acordo com o referido dispositivo, a Coroa deverá ser notificada quando uma corte estiver tendente a fazer uma declaração de incompatibilidade de uma legislação do Parlamento frente ao Human Rights $A c t .{ }^{24}$ A declaração judicial de incompatibilidade será estudada com mais profundidade adiante.

Portanto, o Human Rights Act manteve a tradição e respeito à Coroa.

\section{Direitos fundamentais e o parlamento}

Nesta seção far-se-á a abordagem do Human Rights Act em face da atividade estatal que se encontra em maior destaque atualmente no Reino Unido. E a importância do Parlamento britânico também remonta a raízes históricas.

\section{A "soberania última" do Parlamento britânico}

No estudo sobre a democracia e o Poder Legislativo, o professor José Levi Mello do Amaral Júnior resume os motivos que levaram ao surgimento da democracia parlamentar conhecida nos tempos modernos, in litteris:

A democracia parlamentar começa a tomar forma na Idade Média. Evolui por meio da adoção de mecanismos de limitação e de controle político do poder real. Os Parlamentos surgem para limitar e controlar o poder do rei. ${ }^{25}$

No mesmo sentido, complementa o professor Raul Machado Horta:

Há relação de causalidade entre monarquia constitucional e regime parlamentar. O processo histórico de redução e de controle dos poderes do Monarca e o concomitante fortalecimento dos poderes do Parlamento conduziu ao nascimento do regime parlamentar. A trajetória desse processo é identificável na Inglaterra, nos fins do século XVIII, e nas monarquias constitucionais do século XIX. A institucionalização do poder monárquico

\footnotetext{
${ }^{24} \mathrm{O}$ texto original do referido dispositivo é o seguinte: "Where a court is considering whether to make a declaration of incompatibility, the Crown is entitled to notice in accordance with rules of court." (REINO UNIDO. Human rights act. 1998. 1998 Chapter 42...).

${ }^{25}$ AMARAL JÚNIOR, José Levi Mello do. O Poder Legislativo na Democracia Contemporânea. A função de controle político dos Parlamentos na democracia contemporânea. In: Revista de Informação Legislativa, n. 168 , pp. $7-17$, out./dez. 2005 , p. 8.

PRISMAS: Dir., Pol.Pub. e Mundial., Brasília, v.3, n, 2, p 217-242, jul/dez.2006 
nas regras constitucionais preparou o terreno para a implantação do regime parlamentar. $^{26}$

De fato, o regime parlamentar teve origem no enfraquecimento da monarquia absolutista. E a limitação do "poder divino" do Monarca começou no reinado de João Sem Terra $^{27}$ que, diante de sua política de altos impostos, se viu pressionado pelo exército organizado pelos barões ingleses a assinar a Magna Carta, que "[...] a princípio, constituía-se em pacto ou armistício celebrado entre o rei, o baronato e o Alto Clero da Inglaterra (este, com elevado número de jurisconsultos)..${ }^{28}$

Mas o Rei João Sem Terra e o seu sucessor, Henrique III, não primavam pelo respeito à Magna Carta, o que motivou, no ano de 1258, os barões ingleses a se reunirem em número de 224 a fim de constituir a sua Assembléia, designada oficialmente de Parlamento, com o intuito de controlar o poder real. ${ }^{29}$

Em 1265, um poderoso feudatário, Simon de Monfort, reuniu o Parlamento contra a vontade do rei Henrique III e convocou, também, dois cavaleiros de cada condado e dois burgueses de cada cidade (em razão do que é chamado "pai da Câmara dos Comuns"). O rei Eduardo I, em 1295, consolidou o procedimento, utilizando convocações diretas para os nobres e clérigos e convocações por meio de representantes para o terceiro estado ("Parlamento modelo"). Nas primeiras décadas do século XIV começou a tomar forma o bicameralismo no Parlamento inglês. Foi somente a partir do século XV que começou a se configurar a competência legislativa do Parlamento inglês. Com as revoluções liberais, a função legislativa foi, aí, sim, arrebatada dos reis pelos Parlamentos. ${ }^{30}$

Assim, após uma longa história de lutas para limitar o "poder divino" do Monarca frente à autoridade do Parlamento, que registra até a decapitação de um Rei e a expulsão de outro, firma-se no Reino Unido o princípio da soberania do Parlamento ("Parliamentary sovereignty"), cujos elementos essenciais foram assim caracterizados por Dicey:

I. poder do legislador de modificar livremente qualquer lei, fundamental ou não;

II. ausência de distinção jurídica entre leis constitucionais e ordinárias;

\footnotetext{
${ }^{26}$ Ob. cit., p. 658.

${ }^{27}$ Segundo WINSTON CHURCHILL, “verifica-se que a nação britânica e o mundo de língua inglesa devem muito mais aos vícios de João do que aos trabalhos de soberanos virtuosos; isso porque foi através da união de muitas forças contra ele que se construiu de fato o mais famoso marco de nossos direitos e liberdades." (CHURCHILL, Winston S. História dos povos de língua inglesa. v. I. Tradução Enéas Camargo. São Paulo: IBRASA, pp. 213/214, apud PANIZA, Alexandre de Lima. O paradigma clássico inglês enquanto substrato histórico da doutrina de intervenção internacional para a defesa dos direitos fundamentais. In: Revista brasileira de direito constitucional, n. 4, pp. 191-224, jul./dez. 2004, p. 197.

${ }^{28}$ PANIZA, ob. cit., p. 197. O referido autor traz um amplo estudo sobre a evolução histórica do direito britânico.

${ }^{29}$ Idem, p. 198.

${ }^{30}$ AMARAL JÚNIOR, ob. cit. p. 8.

PRISMAS: Dir., Pol.Pub. e Mundial., Brasília, v.3, n, 2, p 217-242, jul/dez.2006 
III. inexistência de autoridade judiciária ou qualquer outra com o poder de anular um ato do Parlamento ou considerá-lo nulo ou inconstitucional. ${ }^{31}$

O princípio da soberania do Parlamento foi observado pelo Human Rights Act. Todavia, o Human Rights Act gerou também efeitos indiretos ao referido princípio, conforme se observará adiante.

Declaração de compatibilidade perante o parlamento. proteção política dos direitos fundamentais

Pela seção 19 do Human Rights $A c t,{ }^{32}$ antes da leitura do projeto ou proposta de lei, o Ministro encarregado do tema deve apresentar uma declaração de compatibilidade (“statement of compatibility") perante o Parlamento, assegurando que as normas ali previstas são compatíveis com o Human Rights Act, ou outra declaração, afirmando que, embora ele esteja incapacitado de fazer a declaração de compatibilidade, ainda assim o governo deseja que a Câmara continue a debater a lei. ${ }^{33}$

Como é de se presumir, se a segunda declaração acima referida for feita, é de se esperar uma reação contrária da imprensa e da opinião pública em face de uma possível violação dos direitos da Convenção, porquanto nesta segunda hipótese o governo britânico estará assumindo a intenção de derrogar norma do Human Rights Act.

Em verdade, como bem salientou Dawn Oliver, ${ }^{34}$ a declaração de compatibilidade nada mais é do que uma proteção política dos direitos previstos no Human Rights Act, na

${ }^{31}$ DICEY, Albert. Introduction to the study of the law of the Constitution. $9^{\mathrm{a}} \mathrm{ed}$. London: Macmillan and Co., 1950, p. 90/91; apud BARROSO, Luís Roberto. O controle de constitucionalidade no direito brasileiro: exposição sistemática da doutrina e análise crítica da jurisprudência. São Paulo: Saraiva, 2004, p. 42.

${ }^{32}$ O texto original é o seguinte: "19. - (1) A Minister of the Crown in charge of a Bill in either House of Parliament must, before Second Reading of the Bill -

(a) make a statement to the effect that in his view the provisions of the Bill are compatible with the Convention rights ('a statement of compatibility'); or

(b) make a statement to the effect that although he is unable to make a statement of compatibility the government nevertheless wishes the House to proceed with the Bill." (REINO UNIDO. Human rights act. 1998. 1998 Chapter 42...).

${ }^{33}$ E o Parlamento vem cumprindo com o seu dever de fazer a declaração de compatibilidade das legislações por ele produzidas, ainda que em algumas situações esta declaração seja otimista, segundo registram BRADLEY e EWING: "In practice Bills contain such a statement on their face and by 2002 no Bill had been introduced without bearing a statement of compatibility, although in some cases the statement seemed optimistic." (BRADLEY, A.W., and EWING, K.D., ob. cit., p. 423).

${ }^{34}$ Não obstante a proteção política, o referido Autor destaca que, ainda assim, os Atos do Parlamento não estariam livres da oposição da opinião pública, especialmente das minorias que usualmente têm seus direitos restringidos por tais diplomas legislativos: "But it is by no means obvious that public opinion would be on the side of the persons whose rights are being interfered with under statue, especially if, as will often be the case, they are illegal immigrants, suspected paedophiles, drug dealers, and other social pariahs." (OLIVER, Dawn, ob. cit., p. 118).

PRISMAS: Dir., Pol.Pub. e Mundial., Brasília, v.3, n, 2, p 217-242, jul/dez.2006 
medida em que a intenção do governo britânico foi evitar que fosse necessária a análise da compatibilidade dos Atos do Parlamento pelas Cortes judiciais.

Assim, a declaração de compatibilidade acaba por preservar a "soberania última" do Parlamento, uma vez que se buscou através dela que "[...] a responsabilidade última no que concerne ao respeito da Convenção deve repousar nas mãos do Parlamento.". 35

De fato, verifica-se na declaração de compatibilidade perante o Parlamento traços característicos de proteção política dos direitos fundamentais previstos no Human Rights Act. Na concepção trazida por Luís Roberto Barroso, “[...] controle político sugere o exercício da fiscalização de constitucionalidade por órgão que tenha essa natureza, normalmente ligado de modo direito ao Parlamento.". 36

Mas o controle político ${ }^{37}$ exercido pelo Parlamento não se restringe somente à declaração de compatibilidade. Após a vigência do Human Rights Act, foi criado nas duas Casas do Parlamento o Comitê Conjunto de Direitos Humanos ("Joint Committe on Human Rights"), que, dentre outras atribuições, exerce a de examinar minuciosamente a compatibilidade de Cartas em face do Human Rights Act, incitar o governo a fundamentar as declarações de compatibilidade previstas na seção 19, além de examinar as derrogações de cláusulas do Ato feitas pelo governo. ${ }^{38}$

\footnotetext{
${ }^{35}$ HUESCHLING, Luc. État de Droit, Rechtsstaat, Rule of Law. $\mathrm{n}^{\circ} \mathrm{s} 218$ e 219. Paris: Dalloz, p. 317, apud FERREIRA FILHO, Manoel Gonçalves. Inovações na constituição inglesa: o human rights act, 1998...., p. 50 .

36 BARROSO, ob. cit., p. 41. O referido autor lembra que a modalidade de controle político de constitucionalidade está associada à experiência constitucional francesa que, assim como no sistema britânico, rejeita o controle judicial exercido pelos juízes e tribunais.

${ }^{37}$ Cabe ressaltar aqui a opinião diversa de Rodrigo Lopes Lourenço, que defende o uso da expressão "controle não jurisdicional", sob o seguinte fundamento: "Acoimou-se de impróprio o termo 'político' porque, a rigor, político é todo órgão estatal dotado de autonomia de decisão outorgada diretamente pela Constituição.", o que levaria à conclusão de que "...cada órgão jurisdicional de deliberação coletiva, tribunal, ou de deliberação singular, juiz e os órgãos do Ministério Público são órgãos políticos, porque, ainda que sujeitos a controle e limites, não estão hierarquizados entre si, isto é, sua atuação independentiza-se de autorização de órgão superior." (LOURENÇO, Rodrigo Lopes. Controle de constitucionalidade à luz da jurisprudência do Supremo Tribunal. $2^{\mathrm{a}}$ ed. Rio de Janeiro: Forense, 1999, p. 4).

${ }^{38}$ OLIVER, Dawn, ob. cit., p. 118. Em nosso ordenamento jurídico, o Comitê Conjunto de Direitos Humanos poderia ser comparado, com as devidas proporções, às Comissões de Constituição e Justiça da Câmara (art. 32, III, do Regimento Interno da Câmara dos Deputados) e do Senado Federal (art. 101 do Regimento Interno do Senado). Sobre as diversas formas de controle político de competência do Congresso Nacional, vide AMARAL JÚNIOR, ob. cit., pp. 11-15.
}

PRISMAS: Dir., Pol.Pub. e Mundial., Brasília, v.3, n, 2, p 217-242, jul/dez.2006 
Mas talvez maior respeito ao princípio da "soberania última" do Parlamento se encontre na faculdade exclusiva deste em enunciar ordens de reparo na legislação tida por incompatível pelas Cortes Judiciais.

De acordo com a seção 10 do Human Rights Act, o Ministro a quem é dirigida a declaração de incompatibilidade poderá ou não fazer uma ordem de reparo para tornar a legislação compatível com o Ato. O destaque no verbo "poderá" foi proposital, porquanto a ordem de reparo constitui uma faculdade do Ministro, ele não está obrigado a fazê-la. E se não fizer continuará prevalecendo a lei interna, a despeito de ser incompatível com o Human Rights Act.

No entanto, caso o Ministro opte por não fazer a ordem de reparo, certamente ele sofrerá pressão, tanto dentro do Reino Unido como externamente, na medida em que ele estará ratificando que o governo não deseja cumprir as normas da Convenção Européia que subscreveu. Nesse sentido, bem ressalta o professor Manoel Gonçalves Ferreira Filho:

Entretanto, a manutenção da lei tal qual é, em oposição à norma do Human Rights, que na sua parte substantiva, é o Pacto europeu dos direitos fundamentais, certamente coloca muito mal o Reino Unido em face da Corte de Estrasburgo. De fato, se a questão chegar até ela, o condenará por violação do Pacto. Mais ainda, o porá na desagradável situação de descumpridor de normas que subscreveu. ${ }^{39}$

A ordem de reparo inova ao prever um procedimento legislativo simplificado. Basta uma simples resolução, aprovada pelas duas Casas do Parlamento, para que o Ministro derrube o Ato incompatível criado pelo Parlamento. Rompe, assim, com o princípio constitucional inglês de que a lei, especialmente os Atos, só podem ser modificados por um Ato do Parlamento. ${ }^{40}$

Portanto, como visto acima, a ordem de reparo visa conciliar a lei interna com o Human Rights Act, preservando, contudo, a "soberania última" do Parlamento, ao excluir a possibilidade das Cortes Judiciais revogarem a legislação tida por incompatível. Todavia, a "soberania última" do Parlamento não ficou ilesa, ao menos na sua concepção tradicional, com as normas trazidas pelo Human Rights Act, conforme se observará no capítulo seguinte.

\footnotetext{
${ }^{39}$ FERREIRA FILHO, Manoel Gonçalves. Inovações na constituição inglesa: o human rights act...p. 53.

${ }^{40}$ OLIVER, Dawn, ob. cit., p. 115. Segundo Bradley e Ewing: "The stated purpose of this procedure (wich has been criticized as being a new Henry VIII clause) is to enable incompatibility with a Convention right to be removed from the statute book more quickly than if an amending Act of Parliament were needed." ( BRADLEY, A.W., and EWING, K.D., ob. cit., p. 419). 


\section{Direitos fundamentais e o judiciário}

Enfim, o estudo do Judiciário britânico, que talvez tenha sido uma das atividades estatais mais afetadas com a implementação do Human Rights Act. E a mudança trazida pelo referido Ato, aparentemente, não foi ruim.

\section{Dever de interpretação compativel}

A primeira mudança positiva trazida pelo Human Rights Act foi a de que as leis britânicas devem ser interpretadas em consonância com suas normas. Pela seção $3^{\mathrm{a}}$, alínea $1^{\mathrm{a}}$, o juiz deve interpretar e aplicar o direito inglês de um modo "compatível com os direitos da Convenção", ${ }^{41}$ mas isto "na medida do possível". ${ }^{42}$

Segundo Dawn Oliver, esta cláusula tem sido usada pelas Cortes do Reino Unido para ler palavras adicionais na legislação de modo a considerarem-na compatível com o Human Rights Act, ou ler profundamente a legislação para restringir o seu alcance e efetivar a extensão da linguagem a fim de evitar a incompatibilidade. As Cortes não poderão, contudo, em hipótese alguma, fazer nova lei. "Their role is to interpret the law, not to legislate". ${ }^{4}$

\footnotetext{
${ }^{41}$ O texto original é o seguinte: "3. - (1) So far as possible to do so, primary legislation and subordinate legislation must be read and given effect in a way wich is compatible with the Convention rights." (REINO UNIDO. Human rights act. 1998. 1998 Chapter 42...). A referida cláusula se assemelha um pouco com a nossa "interpretação conforme a Constituição" que, na definição dada pelo Supremo Tribunal Federal, é a "... técnica de controle de constitucionalidade que encontra o limite de sua utilização no raio das possibilidades hermenêuticas de extrair do texto uma significação normativa harmônica com a Constituição." (BRASIL, Supremo Tribunal Federal, Tribunal Pleno, Adin 3.046-9/SP, Relator: Min. Sepúlveda Pertence, DF. Diário da Justiça, 28 mai. 2004). Sobre o princípio da interpretação conforme a Constituição, vide BONAVIDES, Paulo. Curso de Direito Constitucional. $14^{\mathrm{a}}$ ed. São Paulo: Malheiros, 2004, pp. 517-524. O referido autor destaca a importância do referido princípio pois ele "[...] não desprestigia a função legislativa nem tampouco enfraquece a magistratura nos poderes de conhecer e interpretar a lei pelo ângulo de sua constitucionalidade.".

${ }^{42}$ Em sentido semelhante, ROBERT ALEXY sustenta um "argumento de otimização" para significar que os direitos fundamentais, em razão do seu caráter principiológico, devem ser realizados na maior medida possível, dentro das possibilidades fáticas e jurídicas. Nas palavras do autor "[...] los principios son normas que ordenan que algo sea realizado en la mayor medida posible, dentro de las posibilidades jurídicas y reales existentes. Por lo tanto, los principios son mandatos de optimización, que están caracterizados por el hecho de que pueden ser cumplidos em diferente grado." (ALEXY, Roberto. Teoría de los derechos fundamentales. Trad. Ernesto Garzón Valdés. Madrid: Centro de Estúdios Políticos y Constitucionales, 2002, p. 86).

${ }^{43}$ Ob. cit., p. 114. O Autor inglês nos dá um exemplo de aplicação da referida cláusula com um caso prático. A Casa dos Lordes fez uma lei que proibia o ato de prestar declaração ou interrogatório sobre qualquer comportamento sexual da vítima de um estupro. A Corte fez uma interpretação compatível da lei para excetuar a sua aplicação nos casos em que esse testemunho ou questionamento fosse necessário para assegurar um julgamento justo, nos termos do art. 16 da Convenção Européia.
}

PRISMAS: Dir., Pol.Pub. e Mundial., Brasília, v.3, n, 2, p 217-242, jul/dez.2006 
Embora aparentemente inofensivo, o dever de interpretação compatível das Cortes influenciou na chamada "soberania" do Parlamento. Isto porque, antes dessa regra, as Cortes sempre tiveram a preocupação de interpretar o Ato de modo a tornar efetiva a intenção do governo expressa num Ato do Parlamento. Para tanto, partiam de um número de presunções, de que, por exemplo, o Parlamento não teria a intenção de legislar de forma incompatível com as obrigações internacionais firmadas pelo Reino Unido.

Atualmente, sob o Human Rights Act, as Cortes têm a função precípua de interpretar a legislação "o máximo possível” para dar preferência as normas do Human Rights Act sobre qualquer outro Ato, ainda que isto represente declarar que o referido Ato é incompatível com o Human Rights Act. $^{44}$

\section{Declaração de incompatibilidade x controle de constitucionalidade}

E se não for possível interpretar a legislação do Reino Unido de forma compatível com os direitos da Convenção? Neste caso, entra em cena a chamada declaração de incompatibilidade ("declaration of incompatibility"), prevista na seção 4 do Human Rights Act, que, para o professor Manoel Gonçalves Ferreira Filho, é o “[...] ponto mais interessante do Human Rights Act [...]". 45

Se a Corte, num caso concreto, verificar a incompatibilidade entre a lei britânica e a norma do Human Rights Act, ela deverá aplicar a lei, mas, simultaneamente, enunciar uma declaração de incompatibilidade. Isto permitirá que o Ministro competente utilize a ordem de reparo para tornar a legislação compatível com o Human Rights Act, conforme visto acima.

Poder-se-ia comparar a declaração de incompatibilidade com o controle de constitucionalidade vigente nos países da Europa continental e das Américas. No entanto, a identidade entre os dois institutos é meramente aparente, pois visível a diferença entre eles. Para melhor ilustrar essa diferença, segue um quadro comparativo entre esses modelos:

\begin{tabular}{|l|l|}
\hline $\begin{array}{c}\text { Declaração de incompatibilidade } \\
\text { (Human Rights } \text { Act) }\end{array}$ & \multicolumn{1}{|c|}{$\begin{array}{c}\text { Controle de constitucionalidade } \\
\text { (modelo norte-americano) }\end{array}$} \\
\hline $\begin{array}{l}\text { - ausência de distinção jurídica entre } \\
\text { normas constitucionais e ordinárias; }\end{array}$ & $\begin{array}{l}\text { as normas constitucionais são } \\
\text { hierarquicamente superiores às normas } \\
\text { ordinárias. }\end{array}$ \\
\hline $\begin{array}{l}\text { - poder do legislador de modificar } \\
\text { livremente qualquer lei, constitucional }\end{array}$ & $\begin{array}{l}\text { - as normas constitucionais, geralmente, } \\
\text { são protegidas contra revogação ou }\end{array}$ \\
\hline
\end{tabular}

\footnotetext{
${ }^{44}$ OLIVER, Dawn, ob. cit., p. 114.

${ }^{45}$ FERREIRA FILHO, Manoel Gonçalves. Inovações na constituição inglesa: o human rights act...p. 53. PRISMAS: Dir., Pol.Pub. e Mundial., Brasília, v.3, n, 2, p 217-242, jul/dez.2006
} 


\begin{tabular}{|l|l|}
\hline ou não; & $\begin{array}{l}\text { emenda ao se exigir um quorum especial } \\
\text { no legislativo ou outra exigência } \\
\text { procedimental. }\end{array}$ \\
\hline $\begin{array}{l}\text { - ocorre sempre num litígio concreto } \\
\text { (difuso), jamais em abstrato, e, ainda } \\
\begin{array}{l}\text { assim, o juiz não tem o poder de } \\
\text { revogar a norma incompatível; }\end{array}\end{array}$ & $\begin{array}{l}\text { - o controle de constitucionalidade pode } \\
\text { ser difuso ou concentrado, sendo que na } \\
\text { "anulada" pelo Poder Judiciário, cuja } \\
\text { decisão tem efeito contra todos; }\end{array}$ \\
\hline $\begin{array}{l}\text { - inexistência de autoridade judiciária } \\
\text { ou qualquer outra com o poder de } \\
\text { anular um ato do Parlamento ou } \\
\text { considerá-lo nulo ou inconstitucional } \\
\text { (princípio da supremacia do do }\end{array}$ & $\begin{array}{l}\text { - O Poder Judiciário é o intérprete final } \\
\text { da constitucionalidade das leis, podendo } \\
\text { anular os efeitos das leis que considere } \\
\text { inconstitucionais (princípio da } \\
\text { supremacia da Constituição). }\end{array}$ \\
\hline
\end{tabular}

Portanto, como se pode observar, a declaração de incompatibilidade também preservou a "soberania última" do Parlamento, uma vez que a declaração enunciada pelas Cortes judiciais não terá o condão de revogar a norma tida por incompatível.

Abre-se é certo caminho para remediar a colisão entre a lei e a norma do Human Rights Act, reconhecida em declaração de incompatibilidade. Isto, porém, preservando-se a soberania - a soberania "última", como dizem os autores ingleses - do Estado, na medida que se fará, ou não se fará, por meio de autoridade política e não judicial, e por meio não de uma declaração de nulidade, mas sim pela edição de normas que alterem a lei. ${ }^{46}$

Mas de um certo ponto de vista a chamada "soberania última" do Parlamento não restou incólume. Em primeiro lugar, será muito difícil para qualquer autoridade pública aplicar a norma tida por incompatível, sabendo que os indivíduos afetados pela referida norma poderão apelar à Corte de Estrasburgo para terem resguardados os seus direitos. E o sucesso em casos como esse será muito provável. ${ }^{47}$

Em segundo lugar, como visto acima, a declaração de incompatibilidade dá ensejo para que o Ministro competente utilize a ordem de reparo, pressionando o Parlamento a modificar a legislação de modo a torná-la compatível com o Human Rights Act. Em última análise, é o Judiciário que estará "incentivando" a atividade legislativa do Parlamento, máxime expressão de sua "soberania última".

Neste enfoque, parece que, realmente, a declaração de incompatibilidade foi o ponto mais interessante do Human Rights Act.

\footnotetext{
${ }^{46}$ FERREIRA FILHO, Manoel Gonçalves. Inovações na constituição inglesa: o human rights act...p. 54.

47 "This dilemma of whether to apply legislation or not after a declaration of incompatibility seems destined for the courts at the highest level.” ( BRADLEY, A.W., and EWING, K.D., ob. cit., p. 419). 


\section{Eficácia dos direitos fundamentais no Reino Unido}

Nas seções anteriores, vimos que o Human Rights Act trouxe mudanças significativas no sistema jurídico-político do Reino Unido, influenciando nas atividades do Monarca, do Parlamento, e do Judiciário britânico. Resta, enfim, saber se a implementação do Human Rights Act tornou de algum modo eficazes os direitos fundamentais no Reino Unido.

Um panorama positivo para essa questão vem logo na seção $1^{\text {a }}$ do Human Rights Act, onde no seu parágrafo segundo está prescrito que o propósito do Ato é tornar efetivos os direitos da Convenção Européia de Direitos Humanos. ${ }^{48}$ E o significado de "tornar efetivo" é elaborado nas seções seguintes do Ato.

Em primeiro lugar, uma Corte judicial do Reino Unido que esteja tratando de uma questão relacionada com os direitos da Convenção deverá sempre observar as decisões da Corte Européia de Direitos Humanos de Estrasburgo ou de outros órgãos do Conselho da Europa, que são responsáveis pela observância da Convenção na lei internacional (seção $2^{\mathrm{a}}$ do $\left.\mathrm{HRA}^{49}\right)$.

Dessa maneira, na interpretação das leis britânicas e no desenvolvimento do common law, a jurisprudência das instituições do Conselho da Europa exercerá influência. Todavia, como bem adverte Dawn Oliver, apesar da influência da jurisprudência das instituições do Conselho da Europa, esta jamais será vinculante, porquanto isto significaria "delegate legislative power to an outside body.". 50

Não obstante, estas disposições certamente influenciarão nas decisões a serem tomadas pelas Cortes do Reino Unido, uma vez que elas saberão que se decidirem de forma

\footnotetext{
${ }^{48}$ O texto original é o seguinte: “ (2) Those Articles are to have effect for the purposes of this Act subject to any designated derogation or reservation (as to which see sections 14 and 15).” (REINO UNIDO. Human rights act. 1998. 1998 Chapter 42...).

49 "2. - (1) A court or tribunal determining a question which has arisen in connection with a Convention right must take into account any-

(a) judgment, decision, declaration or advisory opinion of the European Court of Human Rights,

(b) opinion of the Commission given in a report adopted under Article 31 of the Convention,

(c) decision of the Commission in connection with Article 26 or 27(2) of the Convention, or

(d) decision of the Committee of Ministers taken under Article 46 of the Convention, whenever made or given, so far as, in the opinion of the court or tribunal, it is relevant to the proceedings in which that question has arisen." (REINO UNIDO. Human rights act. 1998. 1998 Chapter 42...).

${ }^{50}$ OLIVER, Dawn, ob. cit., p. 113.

PRISMAS: Dir., Pol.Pub. e Mundial., Brasília, v.3, n, 2, p 217-242, jul/dez.2006 
contrária à jurisprudência da Corte Européia, o indivíduo atingido por essa decisão certamente terá êxito na Corte de Estrasburgo.

Por outro lado, o Reino Unido preferiu não incorporar o artigo $13^{\circ}$ da Convenção Européia de Direitos Humanos. O referido artigo assegurava que existiriam remédios eficazes contra as violações dos direitos da Convenção.

A não-incorporação do mencionado artigo $13^{\circ}$ tem suas razões no peculiar sistema jurídico britânico que, como visto, preferiu prever no Human Rights Act remédios típicos, tais como as declarações de compatibilidade e incompatibilidade e as ordens de reparo, que, embora não sejam tão "eficazes" para o fim de evitar as violações dos direitos da Convenção Européia, certamente preservam princípios tradicionais do Reino Unido como o da soberania última do Parlamento.

Outras questões relacionadas com a eficácia dos direitos fundamentais no Reino Unido merecem uma análise mais detalhada, o que será feito a seguir nos dois últimos tópicos desta exposição.

\section{Eficácia vertical e horizontal}

Pela seção $6^{\text {a }}$ do Human Rights $A c t,{ }^{51}$ é ilegal que uma autoridade pública haja de uma forma incompatível com os direitos da Convenção Européia, a não ser que esta ação esteja autorizada por uma legislação primária e aquela autoridade não possa agir diferente.

De acordo com o referido dispositivo, a autoridade pública estará sempre respondendo pelos atos que pratiquem e violem os direitos da Convenção. ${ }^{52} \mathrm{~A}$ responsabilidade dela, contudo, será sempre de natureza civil, nos termos do parágrafo $8^{\circ}$ da seção $7^{\mathrm{a}} .^{53}$

51 “6. - (1) It is unlawful for a public authority to act in a way which is incompatible with a Convention right.

(2) Subsection (1) does not apply to an act if-

(a) as the result of one or more provisions of primary legislation, the authority could not have acted differently; or

(b) in the case of one or more provisions of, or made under, primary legislation which cannot be read or given effect in a way which is compatible with the Convention rights, the authority was acting so as to give effect to or enforce those provisions." (REINO UNIDO. Human rights act. 1998. 1998 Chapter 42...).

52 DAWN OLIVER identifica no referido dispositivo um enfraquecimento da harmonia entre as cortes e o executivo onde as decisões ministeriais forem consideradas ofensivas ao Ato. Todavia, alerta que as cortes não devem interferir em decisões usualmente sensíveis e altamente políticas sobre interesse público, como, por exemplo, a segurança nacional, em prol de assegurar os direitos da Convenção. (ob. cit., p. 116).

53 "(8) Nothing in this Act creates a criminal offence." (REINO UNIDO. Human rights act. 1998. 1998 Chapter $42 \ldots)$.

PRISMAS: Dir., Pol.Pub. e Mundial., Brasília, v.3, n, 2, p 217-242, jul/dez.2006 
Nos parágrafos da seção $6^{\text {a }}$ do Human Rights Act se encontram os entes que o Ato considera autoridade pública. São eles as cortes ou tribunais, e qualquer pessoa ou entidade, pública ou privada, cuja atividade tenha natureza pública.

Neste ponto duas considerações merecem ser feitas.

A primeira delas, trazida por Dawn Oliver ${ }^{54}$, acerca do problema que surge pela falta de definição legal no Reino Unido do que seja uma "função pública". Para o referido autor, existem dois tipos de autoridade pública na seção $6^{a}$ do Human Rights Act: aquelas consideradas padrões, tais como os Ministros, autoridades locais e polícia, cujos atos estão sempre vinculados ao Human Rights Act; e as chamadas autoridade públicas funcionais ("functional public authorities"), que são organismos privados que exercitam algumas funções públicas e que somente estarão submetidos ao Human Rights Act quando estiverem exercendo essa função pública. ${ }^{55}$

A falta de definição do que seja uma "função pública" preocupa quando o órgão que estiver exercendo a função for privado, e causa problemas especialmente quando ele estiver exercendo uma atividade que usualmente é praticada por uma autoridade pública.

O próprio Dawn Oliver nos dá um exemplo prático que é elucidativo. Digamos que a atividade de fornecer abrigos e assistência social está sendo feita por uma autoridade local. Se esta tarefa é considerada como uma função pública ou não, o fato é que os "pacientes" sempre terão a proteção dos seus direitos da Convenção resguardados.

Se, no entanto, este serviço de abrigo e assistência social é transferido para um organismo privado, estes mesmos pacientes perderão a proteção dos seus direitos da Convenção caso este serviço não seja considerado como uma função pública. A falta de definição do que seja função pública, portanto, traz a insegurança e o risco de se dar proteção aos direitos da Convenção para alguns e não dar para outros em uma mesma situação, a

\footnotetext{
${ }^{54}$ Ob. cit., pp. 116/117.

${ }^{55}$ Tratando sobre a eficácia vinculante dos direitos fundamentais sobre o Poder Executivo no âmbito do direito lusitano, JOSÉ JOAQUIM GOMES CANOTILHO ressalta que a mesma alcança não apenas o órgão, mas também a função. Dessa forma, quer numa perspectiva formal organizatória, quer numa perspectiva funcional, as pessoas jurídicas de direito público ainda que atuem na esfera privada e as pessoas jurídicas de direito privado que exerçam atribuições de natureza pública vinculam-se aos direitos fundamentais (CANOTILHO, José Joaquim Gomes. Direito Constitucional e Teoria da Constituição. $7^{\mathrm{a}}$. ed. Coimbra: Almedina, 2003, p. 442).

PRISMAS: Dir., Pol.Pub. e Mundial., Brasília, v.3, n, 2, p 217-242, jul/dez.2006 
depender se a atividade estar sendo exercida por uma autoridade pública padrão ou um organismo privado. ${ }^{56}$

Dessa maneira, enquanto não for editada uma lei "regulamentando" o que seja "função pública" para os fins previstos seção $6^{\mathrm{a}}$ do Human Rights Act, parece que a árdua tarefa de resolver situações como esta caberá às Cortes judiciais. ${ }^{57}$

A outra questão que merece destaque é saber se, ao prever expressamente a autoridade privada como possível sujeito transgressor dos direitos da Convenção, estaria o Human Rights Act consagrando a eficácia horizontal dos direitos fundamentais no Reino Unido.

Antes de se analisar esta questão, cumpre fazer algumas breves considerações sobre a teoria da eficácia horizontal dos direitos fundamentais.

Os direitos fundamentais foram originariamente concebidos em face do Estado, oponíveis pelo cidadão contra a atividade estatal. Hoje em dia, se fala, naturalmente, ${ }^{58} \mathrm{em}$ eficácia dos direitos fundamentais contra particulares, também chamada de eficácia horizontal dos direitos fundamentais,

[...] para sublinhar o fato de que tais direitos não regulam apenas as relações verticais de poder que se estabelecem entre Estado e cidadão, mas incidem também sobre relações mantidas entre pessoas e entidades não estatais, que se encontram em posição de igualdade formal. ${ }^{59}$

As três principais teorias sobre a eficácia horizontal dos direitos fundamentais são as seguintes.

Teoria negativa de eficácia dos direitos fundamentais na esfera privada: é a concepção clássica, no sentido de que os direitos fundamentais limitam apenas o Estado, não

\footnotetext{
${ }^{56}$ É a mesma conclusão que DAWN OLIVER chega no exemplo acima narrado: "But it is anomalous that, for instance, those whose housing or care are provided directly by Standard public authorities are entitled to rely on Convention rights, and those receiving the same services from private bodies are not so entitled." (ob. cit., p. 116).

${ }^{57}$ Como também parecem pensar BRADLEY e EWING: "But although the definition of public authority and public function should be given a 'generous interpretation', it is clear that the courts 'will need to weigh up a number of factors' to determine whether a body is a public authority for the purposes of the Human Rights Act.” (BRADLEY, A.W., and EWING, K.D., ob. cit., p. 410).

${ }^{58}$ SARLET aponta relativo consenso doutrinário a respeito de algum tipo de eficácia dos direitos fundamentais nas relações privadas, especialmente em "[...] situações de desigualdade gerada pelo exercício de um maior ou menor poder social." (SARLET, Ingo Wolfgang. A eficácia dos direitos fundamentais. 3. ed. Porto Alegre: Livraria do Advogado, 2003, p. 357). Em sentido semelhante, essa constatação também é efetuada por ALEXY nos seguintes termos: "[...] actualmente se acepta, en general, que las normas iusfundamentales influyen en la relación ciudadano/ciudadano $\mathrm{y}$, en este sentido, tienen un efecto en terceros o un efecto horizontal. Lo que se discute es cómo y en que medida ejercen esta influencia" (ALEXY, Roberto. Teoría de los derechos fundamentales. Trad. Ernesto Garzón Valdés. Madrid: Centro de Estúdios Políticos y Constitucionales, 2002, p. 510/511).

${ }^{59}$ SARMENTO, Daniel. Direitos Fundamentais e Relações Privadas. Rio de Janeiro: Lúmen Juris, 2004, p. 5.

PRISMAS: Dir., Pol.Pub. e Mundial., Brasília, v.3, n, 2, p 217-242, jul/dez.2006 
vinculando direta ou indiretamente os particulares. "Os particulares, no domínio das suas relações recíprocas, não podem invocar a Constituição, mas apenas os direitos previstos na legislação civil.”. ${ }^{60}$ Tem amplo prestígio no direito norte-americano.

\section{Teoria da eficácia indireta e mediata dos direitos fundamentais na esfera}

privada: concepção dominante no direito germânico, esta teoria nega a possibilidade de aplicação direta dos direitos fundamentais nas relações privadas, uma vez que isto implicaria em acabar com a autonomia da vontade, menosprezando o direito privado ao transformá-lo numa mera concretização do direito constitucional. Caberia ao legislador e não ao juiz a tarefa de conformação dos direitos fundamentais no âmbito privado, ${ }^{61}$ restando a este apenas "o papel de preencher as cláusulas indeterminadas criadas pelo legislador, levando em consideração os direitos fundamentais ". 62

\section{Teoria da eficácia direta e imediata dos direitos fundamentais na esfera} privada: é majoritária na Espanha, Portugal, Itália e Argentina. Funda-se, em síntese, na premissa de que os direitos fundamentais "podem ser invocados diretamente nas relações privadas, independentemente de qualquer mediação por parte do legislador, revestindo-se de oponibilidade erga omnes". 63

Assim, conforme esta teoria, os direitos fundamentais seriam direitos subjetivos oponíveis tanto nas relações de direito público, quanto nas relações de direitos privado, com a peculiaridade de que, neste último caso, o direito fundamental diretamente aplicado deve ser harmonizado e compatibilizado, por meio da ponderação de bens, com o princípio da autonomia privada. ${ }^{64}$

Feitas essas considerações, voltemos ao Reino Unido. Será que a seção $6^{\mathrm{a}}$ do Human Rights Act consagrou a eficácia horizontal dos direitos fundamentais no Reino Unido?

\footnotetext{
${ }^{60}$ SARMENTO, Daniel, ob. cit., p. 227.

${ }^{61}$ Nesse sentido é a preocupação de KONRAD HESSE, partidário da eficácia meramente mediata dos direitos fundamentais nas relações entre particulares, em delimitar a competência do legislador infraconstitucional e do Judiciário: “[...] os direitos fundamentais, em geral, não podem vincular diretamente privados. Ter em conta sua influência sobre o direito privado como parte da ordem jurídica total é [...], em primeiro lugar, tarefa do legislador de direito privado - vinculado aos direitos fundamentais - a quem cabe, em suas regulações, concretizar o conteúdo jurídico dos direitos fundamentais [...]. Os tribunais não devem corrigir as decisões $\mathrm{e}$ ponderações do legislador em intervenções sobre direitos fundamentais ou com apoio em suas próprias ponderações." (HESSE, Konrad. Elementos de Direito Constitucional da República Federal da Alemanha. Trad. Luis Afonso Heck. Porto Alegre: Sergio Antonio Fabris, 1998, p. 285).

${ }^{62}$ Idem, p. 241.

${ }^{63}$ Idem, p. 245.

${ }^{64}$ SARMENTO ressalta que "[...] a fixação de limites para a incidência dos direitos fundamentais nas relações entre particulares envolve um problema de ponderação com a autonomia privada" (SARMENTO, Daniel. Direitos fundamentais e relações privadas. Rio de Janeiro: Lúmen Júris, 2004, p. 302).
} 
Parece que Dawn Oliver vislumbrou a consagração da teoria indireta dos direitos fundamentais no Reino Unido após a implementação do Human Rights Act. ${ }^{65}$ No entanto, o próprio autor traz exemplos de casos práticos em que se acenou para a adoção da teoria da eficácia direta dos direitos fundamentais.

De fato, no âmbito do direito à privacidade, os direitos fundamentais previstos no Human Rights Act foram assegurados de forma direta contra violações causadas por particulares. As cortes achavam antes do Human Rights Act, no caso de Kaye x Robertson ([1991] FSR 62), que a entrada de jornalistas em quartos de hospitais para reportarem a condição de famosos atores de televisão em coma não seria uma violação ao seu direito de privacidade, porquanto tal direito não existia em norma interna do Reino Unido. O fato da incorporação do artigo $8^{\circ}$ da Convenção Européia fez as cortes aceitarem não somente o direito a privacidade contra autoridades públicas, como também uma common law contra organismos privados, especialmente a imprensa.

Da mesma maneira, no caso Douglas x Hello Ltd ([2001] 2 WLR 992, CA), a Corte de Apelação indicou que existe common law ao direito de privacidade que é violado quando jornalistas tiram e publicam fotografias de casamento sem o consentimento dos noivos, e que um efeito do Human Rights Act é fazer nascer um direito horizontal à privacidade entre o indivíduo e a imprensa. ${ }^{66}$

Polêmicas à parte, o fato é que, após a implementação do Human Rights Act, aumentou-se a proteção que os indivíduos terão contra abusos de seus direitos praticados não somente por uma autoridade pública, mas também por organismos particulares, o que é um avanço considerável.

\section{Derrogações}

Por fim, outra questão relacionada à eficácia dos direitos fundamentais no Reino Unido é a possibilidade de o governo derrogar cláusulas da Convenção Européia em tempos de guerra ou em outra situação emergencial que ameace a vida da nação. Neste sentido, o artigo 15 da Convenção Européia foi derrogado, visando prevenir o terrorismo proveniente da Irlanda do Norte.

\footnotetext{
65 "The most likely development in my view is that the courts will develop the common law so as to make it compatible with Convention rights, but without applying the Convention rights explicitly and directly." (ob. cit., p. 117).

${ }^{66}$ OLIVER, Dawn, ob. cit., p. 117.

PRISMAS: Dir., Pol.Pub. e Mundial., Brasília, v.3, n, 2, p 217-242, jul/dez.2006 
Em 18 de dezembro de 2001, o governo britânico derrogou o artigo $5^{\circ}$ da Convenção Européia (direito à liberdade e segurança), através do Ato de Antiterrorismo, Crime e Segurança de 2001, a fim de permitir a detenção de suspeitos de serem terroristas, contra os quais não há evidências suficientes para uma acusação formal e que não podem ser expulsos ou deportados do Reino Unido. Em novembro de 2005, a Câmara dos Comuns rejeitou proposta do governo britânico de emendar o Ato de Antiterrorismo para aumentar de 14 para 90 dias o período em que suspeitos de atos terroristas podem ser detidos pela polícia britânica, sem uma acusação formal, segundo notícia do jornal Folha de São Paulo. ${ }^{67}$

Tanto o Comitê Conjunto de Direitos Humanos quanto o Comitê de Assuntos Internos da Casa dos Comuns questionaram a necessidade de derrogação implementada pelo Ato de Antiterrorismo, Crime e Segurança de 2001. No verão de 2002, o Comitê Conjunto de Direitos Humanos instaurou um inquérito para saber se ainda continuava a justificativa para a derrogação do terrorismo e, dentre os pontos debatidos, um dos mais importantes foi o de saber que procedimentos no Parlamento e governo poderiam ser aperfeiçoados para assegurar um adequado exame parlamentar da derrogação, não apenas sobre a Convenção Européia de Direitos Humanos, mas sob qualquer Carta de direitos ratificada pelo Reino Unido. ${ }^{68}$

O instituto da derrogação, caso banalizado, sem dúvida acabará por enfraquecer o Human Rights Act e, conseqüentemente, diminuirá a eficácia dos direitos fundamentais no Reino Unido. Isto porque, como bem ressaltado pelo professor Manoel Gonçalves Ferreira Filho, "tais derrogações relativizam a sua importância, pois o tornam inaplicável aos problemas mais candentes da atualidade britânica." 69

A situação emergencial deve ser limitada no tempo. "Se ela não for limitada no tempo, não haverá, no fundo, suspensão de garantias mas sim supressão de garantias". ${ }^{70} \mathrm{~A}$ histeria causada pela onda global do terrorismo ${ }^{71}$ não pode ser desculpa para a supressão dos direitos fundamentais do cidadão, seja no Reino, seja em qualquer lugar do mundo. Se a política de derrogações de direitos previstos no Human Rights Act continuar no Reino Unido,

\footnotetext{
${ }^{67}$ SÃO PAULO. Folha de São Paulo. Folha On Line. Mundo. "Parlamento britânico rejeita proposta antiterror de Blair". 9.11.2005. Disponível em: < www1.folha.uol.com.br/folha/mundo/ult94u89398.shtml>. Acesso em 2 abri. 2006.

${ }^{68}$ OLIVER, Dawn, ob. cit., p. 118.

${ }^{69}$ FERREIRA FILHO, Manoel Gonçalves. Inovações na constituição inglesa: o human rights act...p. 52.

${ }^{70}$ FERREIRA FILHO, Manoel Gonçalves. Direitos humanos fundamentais. $7^{\mathrm{a}}$ ed., São Paulo: Saraiva, 2005 , p. 138.

${ }^{71}$ Sobre o regime de emergência e sugestões para remediá-lo, vide ACKERMAN, Bruce. The emergency constitution. In: The Yale Journal, 3.5.2004.
}

PRISMAS: Dir., Pol.Pub. e Mundial., Brasília, v.3, n, 2, p 217-242, jul/dez.2006 
muitas vítimas inocentes poderão sofrer as conseqüências disso. Basta lembrar o que aconteceu com o brasileiro Jean Charles. ${ }^{72}$

\section{Conclusão}

O Human Rights Act revolucionou, na medida do possível, o sistema jurídicopolítico do Reino Unido. Trouxe profundas alterações nas atividades do Monarca, do Parlamento, e do Judiciário britânico, afetando, ainda, a relação entre eles.

Que o Human Rights Act trouxe avanços ao direito inglês, ninguém duvida. Novidades trazidas pelo Ato, tais como o reconhecimento da responsabilidade de particulares similar à das autoridades públicas quanto às violações aos direitos da Convenção; o especial papel constitucional dos juízes observarem os princípios ali insertos; o controle parlamentar quanto à compatibilidade das normas que edita em face do referido Ato, são dignos de louvor numa sociedade que venera a perenidade de suas tradições.

Marca, por sua vez, como bem ressalta o professor Manoel Gonçalves Ferreira Filho, "a persistência de idéias, como a da soberania 'última', de que decorre a prevalência do direito interno sobre as normas internacionais. E isto no âmbito de um Estado integrado numa ‘comunidade', como o é a União Européia.". 73

Parodiando uma famosa frase pronunciada quando o primeiro homem chegou à lua, o Human Rights Act pode até ser um pequeno passo para assegurar os direitos fundamentais do cidadão, mas é certamente um enorme passo para uma nação tão peculiar como é a britânica.

Artigo recebido em agosto de 2006

Aceito em setembro de 2006

\footnotetext{
${ }^{72} \mathrm{O}$ brasileiro foi assassinado com oito tiros (sete na cabeça e um no ombro) pela policia britânica numa estação de metro em Londres após ter sido confundido com um terrorista. Apesar do Primeiro-Ministro ter pedido desculpas pelo incidente (SÃO PAULO. Folha de São Paulo. Folha On Line. Mundo. "Blair pede desculpas a Lula por morte de Jean Charles". 9.3.2006. Disponível em: < www1.folha.uol.com.br/folha/mundo/ult94u89398.shtml . Acesso em 2 abri. 2006), até hoje não se tem notícias de qualquer punição dos envolvidos no crime nem de reparação à família da vítima.

${ }^{73}$ FERREIRA FILHO, Manoel Gonçalves. Inovações na constituição inglesa: o human rights act...pp. 54/55.

PRISMAS: Dir., Pol.Pub. e Mundial., Brasília, v.3, n, 2, p 217-242, jul/dez.2006 


\section{Referências}

ALEXY, Roberto. Teoría de los derechos fundamentales. Trad. Ernesto Garzón Valdés. Madrid: Centro de Estúdios Políticos y Constitucionales, 2002.

AMARAL JÚNIOR, José Levi Mello do. O Poder Legislativo na Democracia Contemporânea. A função de controle político dos Parlamentos na democracia contemporânea. In: Revista de Informação Legislativa, n. 168, pp. 7-17, out./dez. 2005.

BARROSO, Luís Roberto. O controle de constitucionalidade no direito brasileiro: exposição sistemática da doutrina e análise crítica da jurisprudência. São Paulo: Saraiva, 2004.

BONAVIDES, Paulo. Curso de Direito Constitucional. 14 ed. São Paulo: Malheiros, 2004.

BRADLEY, A.W., and EWING, K.D. Constitucional and Administrative Law. 13. ed., London: Longman, 2003.

BRASIL. Constituição Federal. Código Civil. Código de Processo Civil. Organizador Yussef Said Cahali. 5. ed. ver., atual. e ampl. São Paulo: RT, 2003.

BRASIL. Supremo Tribunal Federal, Tribunal Pleno, Adin 3.046-9/SP, Relator: Min. Sepúlveda Pertence, DF. Diário da Justiça, 28 mai. 2004.

CANOTILHO, José Joaquim Gomes. Direito constitucional e teoria da constituição. 7. ed., Coimbra: Almedina, 2003.

FERREIRA FILHO, Manoel Gonçalves. Curso de direito constitucional. 29. ed., São Paulo: Saraiva, 2002.

.. Direitos humanos fundamentais. 7. ed., São Paulo: Saraiva, 2005.

. Inovações na constituição inglesa: o human rights act, 1998. In: Revista brasileira de direito constitucional, n. 4, pp. 49-55, jul./dez. 2004.

HESSE, Konrad. Elementos de direito constitucional da República Federal da Alemanha. Trad. Luis Afonso Heck. Porto Alegre: Sergio Antonio Fabris, 1998.

HORTA, Raul Machado. Direito constitucional. 4. ed., Belo Horizonte: Del Rey, 2003.

LOURENÇO, Rodrigo Lopes. Controle de constitucionalidade à luz da jurisprudência do Supremo Tribunal. 2. ed. Rio de Janeiro: Forense, 1999.

OLIVER, Dawn. Constitucional reform in the UK. Nova York: Oxford University Press, 2003, p. 111-130.

PANIZA, Alexandre de Lima. O paradigma clássico inglês enquanto substrato histórico da doutrina de intervenção internacional para a defesa dos direitos fundamentais. In: Revista brasileira de direito constitucional, n. 4, pp. 191-224, jul./dez. 2004. 
PINHEIRO, Carla. Direito internacional e direitos fundamentais. São Paulo: Atlas, 2001.

PINTO FILHO, Francisco Bilac M. A Monarquia Constitucional no Reino Unido e a prerrogativa da Coroa. A Desmistificação do honorífico. In: Revista Forense, V. 380, pp. 4763, jul./agost. 2005.

REINO UNIDO. Human rights act. 1998. 1998 Chapter 42. Crown Copyright 1998.

Disponível em: < www.opsi.gov.uk/acts/acts1998/19980042.htm>. Acesso em 2 nov. 2005.

SÃO PAULO. Folha de São Paulo. Folha On Line. Mundo. "Parlamento britânico rejeita proposta antiterror de Blair". 9.11.2005. Disponível em: <

www1.folha.uol.com.br/folha/mundo/ult94u89398.shtml>. Acesso em 2 abri. 2006.

.Blair pede desculpas a Lula por morte de Jean Charles". 9.3.2006. Disponível em: < www1.folha.uol.com.br/folha/mundo/ult94u89398.shtml>. Acesso em 2 abri. 2006.

SARMENTO, Daniel. Direitos Fundamentais e Relações Privadas. Rio de Janeiro: Lúmen Juris, 2004.

SARLET, Ingo Wolfgang. A eficácia dos direitos fundamentais. 3. ed., Porto Alegre: Livraria do Advogado, 2003. 


\section{Resumo}

Trata-se de trabalho que visa analisar os direitos fundamentais no Reino Unido após a implementação e vigência do Human Rights Act em outubro de 2000. Para tanto, faz-se um estudo preliminar acerca da origem e natureza jurídica do Human Rights Act. Em seguida, procede-se com uma abordagem sobre o impacto do Human Rights Act no âmbito dos três poderes estatais do Reino Unido: Executivo, Legislativo e Judiciário. Antes de se chegar à conclusão deste trabalho, passa-se, ainda, por uma análise crítica acerca da eficácia dos direitos fundamentais no Reino Unido diante do referido diploma legal para, ao final, concluir-se de acordo com tudo o que foi exposto, no texto, apresentando impressões e sugestões sobre o assunto, esperando, assim, dar uma modesta contribuição a um tema tão importante e em destaque atualmente no cenário internacional.

Palavras-chave: Direitos Humanos. Direitos Fundamentais. Reino Unido. Human Rights Act
The objective of this paper is to analyze the fundamental rights in the United Kingdom after the Human Rights Act came into force and was implemented in October of 2000. For that purpose, the study addresses a preliminary study on the origin and juridical nature of the Human Rights Act. Following suit, it approaches the impact of the Human Rights Act on the Executive, Legislative, and Judiciary powers in the United Kingdom. Prior to conclusion, the study offers a critical analysis on the effectiveness of the fundamental rights in United Kingdom before the mentioned law. At last, it presents impressions and suggestions on the topic, in an attempt to make a humble contribution to a very important and relevant issue in the present international scenario.

Key words: Human Rights. Fundamental Rights. United Kingdom. Human Rights Act 